\title{
20 Testing the Relevance of Major Social Enterprise Models in Western Europe
}

\author{
Jacques Defourny, Marthe Nyssens and \\ Olivier Brolis
}

\section{Introduction}

Although the notions of social entrepreneurship, social entrepreneur and social enterprise have sometimes been considered as different facets of a same phenomenon, especially in the late 1990s and early 2000s, the last two decades have witnessed clear trends towards distinct research developments about social entrepreneurship (and the related term of social entrepreneur), on the one hand (Dacin et al. 2011; Santos 2012; Alegre et al. 2017, among many others), ${ }^{1}$ and social enterprise, on the other hand ${ }^{2}$ - though, of course, this does not mean that the boundaries between these two research fields are clear cut. In addition to such trends, many conceptual debates are still taking place within each of both "sides", and in particular in the field of research on the concept of social enterprise (SE), which is at the heart of this book as well as of this final chapter. Indeed, the lack of a shared understanding and definition of social enterprise is today acknowledged by most researchers, and it even seems reasonable to speak of the "impossibility of reaching a unified definition of social enterprise".

In response to such conceptual diversity and sometimes confusion, various authors tried to identify categories or types of social enterprise and to propose basic typologies. Alter (2007) was among the first; she put forward various types of operational models, for instance in terms of relations between social enterprises' missions and economic activitieswhich can be, according to the terminology she proposed, missioncentric, mission-related or mission-unrelated. A bit later, Spear et al. (2009) identified four main types of social enterprise in the UK, according to the initiatives' origins and development paths. For the same country, Teasdale (2012) and Gordon (2015) stressed the diversity of discourses or "basic values" shaping SE models, while McMurtry and Brouard (2015) put forward a typology adapted to the Canadian context. For their part, relying mainly on an analysis of the US SE landscape, Young et al. (2016) proposed the metaphor of a "social enterprise zoo", in which different types of animals seek different things-just like 


\section{Defourny, Nyssens \& Brolis}

social enterprises, which differ significantly from each other in the ways in which they combine social and market goals.

When it comes to international comparative works, Kerlin (2013, 2017) adopted an institutional perspective inspired by the "social origins" theory developed by Salamon et al. (2000), identifying key features of macroinstitutional frameworks to suggest how any set of socioeconomic and regulatory institutions at country level tends to shape a specific major SE model per country. Borzaga and Defourny (2001), for the countries that then made up the European Union; Borzaga et al. (2008), for Central and Eastern Europe; Defourny and Kim (2011), for Eastern Asia; and more recently, the European Commission (2020), for the whole of Europe, all made attempts at international comparative analyses, but these analytical grids did not rely on systematic data collection at the enterprise level. ${ }^{3}$

Against such background, we developed a typology of SE models (Defourny and Nyssens 2017), which we also present in the introductory chapter of this book (see section 20.2, about the second phase of the ICSEM Project). This typology highlighted four major SE models: the entrepreneurial non-profit (ENP), the social cooperative (SC), the social business (SB) and the public social enterprise (PSE). As we show, this typology is rooted in theoretical grounds provided by some inspiring works carried out by Gui (1991) and Hansmann (1996) on the very identity of the "third sector". 4

The main objective of this final chapter is to test statistically, at the enterprise level, the relevance of this typology of SE models on the basis of a dataset resulting from a field survey carried out on social enterprises in more than 40 countries across the world. On such basis, we put forward the hypothesis that this typology is neither country-specific nor even, more broadly, context-specific. In other words, we will try to see to what extent each SE model may be identified across countries in every region and across world regions. In such broad perspective, we carried out the statistical testing both at the worldwide level and at the regional level. In line with the whole content of this book, this final chapter of course focuses on Western Europe and on the statistical exploitation of the data collected in this region.

This chapter is organised as follows. We first present the methodology adopted for the empirical survey that is at the very heart of this statistical work: we describe the key dimensions of social enterprise that were captured and the methodological choices that were made for this survey, which was carried out on 721 social enterprises operating in various world regions (section 20.1). We then present the hierarchical cluster analysis that we carried out on the basis of such an outstanding dataset (section 20.2), before discussing the empirical results obtained, especially regarding the existence (or not) of our four theorised SE models (section 20.3). Finally, we conclude with comparisons between the various regions to better apprehend specificities of SE models in their respective contexts. 


\subsection{The ICSEM Survey and Database}

All the researchers involved in the ICSEM Project first had to provide a "country contribution" about the SE landscape in their respective countries. Among other things, researchers were asked to identify and characterise the various SE types or categories they could observe (phase 1 of the ICSEM Project; for a more detailed description of this phase, see the introductory chapter in this volume). Two major distinctive features of this approach should be underlined here. First, no a priori strict definition of social enterprise was imposed for these national contributions. We broadly delineated the field of analysis as "made of organisations that combine an entrepreneurial dynamic to provide services or goods with the primacy of their social aims". The emphasis was put on the embeddedness of the SE phenomenon in local contexts. Secondly, most research was carried out by teams rather than by individual researchers, and this fostered discussion at the local or national level, thereby reducing the risks of biases induced by purely personal perceptions.

In a second phase, in order to address the lack of reliable datasets at enterprise level to undertake international comparative analysis, in-depth information was collected about social enterprises on the basis of a common questionnaire. More precisely, ICSEM research partners interviewed the managers of three to five social enterprises that were deemed emblematic of each SE type identified in the project's first phase. The researchers were asked to collect information regarding more specifically the nature of the social mission or social aims, the type of economic model and the governance structure, as we hypothesised that these three dimensions particularly informed the diversity of social enterprises. Let us recall, in this regard, that the EMES SE ideal type relies on these three dimensions. For each of them, a set of three indicators is put forward. It does not mean, though, that an organisation has to meet all the indicators in order to qualify as a social enterprise; the ideal type is rather used as a yardstick for the comparison and grouping of observed organisations.

As a result, detailed data were collected in a rather homogenous way for 721 social enterprises from 43 countries. Needless to say, such a sample is by no way representative of the SE population across the world. Indeed, not only is the distribution across continents particularly uneven, with a quasi-absence of Africa; more fundamentally, the whole SE population is simply unknown, as there is no universal definition of social enterprise. ${ }^{5}$

As shown in table 20.1, the nineteen European countries covered by the survey account for almost half of all the enterprises surveyed across the world (328 enterprises out of 721). Thanks to the high number of observed social enterprises in Europe, the statistical work could be carried out in separate ways for Western Europe (with 164 surveyed social 
Table 20.1 Social enterprises covered by the ICSEM survey by region/country

\begin{tabular}{lcc}
\hline Regions and countries & $\begin{array}{c}\text { No. of } \\
\text { countries }\end{array}$ & $\begin{array}{c}\text { No. of social } \\
\text { enterprises }\end{array}$ \\
\hline Europe & 19 & 328 \\
Central and Eastern Europe & 7 & 164 \\
Western Europe & 12 & 164 \\
$\quad$ Austria & & 3 \\
$\quad$ Belgium & & 23 \\
$\quad$ Finland & 4 \\
$\quad$ France & & 11 \\
$\quad$ Germany & & 35 \\
$\quad$ Ireland & & 12 \\
$\quad$ Italy & & 13 \\
$\quad$ Luxembourg & & 16 \\
$\quad$ Spain & & 14 \\
$\quad$ Sweden & 5 \\
$\quad$ Unitzerland & & 21 \\
Asia Kingdom & & 7 \\
Latin America & 9 & 100 \\
US, Canada, Australia and New Zealand & 7 & 162 \\
Middle East (Israel and United Arab Emirates) & 4 & 45 \\
Africa (Rwanda and South Africa) & 2 & 31 \\
Total & 2 & 55 \\
\hline
\end{tabular}

enterprises from twelve countries) and Central and Eastern Europe (with 164 surveyed social enterprises from seven countries). In this volume dedicated to social enterprise in Western Europe, we of course focus mostly on findings for Western Europe. ${ }^{6}$

In spite of limitations in the collection of data at the enterprise level, we argue that our overall research strategy-which combines a theoretical typology and a quite demanding bottom-up empirical approach based on a field survey-constitutes a significant step toward capturing the diversity of SE models. The following step (phase 3 of the ICSEM Project) aimed to exploit the dataset built through the ICSEM survey in order to see if it provided empirical support to the typology of SE models mentioned above and described in more detail in section 2 of the introductory chapter in this volume.

\subsection{A Hierarchical Cluster Analysis to Identify Major SE Categories}

For the purpose of carrying out a cluster analysis, we extracted quantitative and qualitative (nominal and ordinal) variables from the questionnaire. The ultimate goal was to describe each of the 164 social enterprises from Western Europe along five major dimensions: (1) 
general identity (legal form, origin, accreditations); (2) social mission (mission's nature, relation with the social enterprise's main economic activity, price of the goods and services provided, type of innovation); (3) workforce composition (workers and volunteers); (4) financial structure in general and, more precisely, ways in which the social enterprise combines various types of resources; and (5) governance structure and rules regarding the allocation of surplus. As multiple choices and combinations of several choices were possible for many questions, we defined 141 variables.

Before undertaking a hierarchical cluster analysis (HCA) based on Ward's aggregation method, we had to solve two main issues. First, our database included both quantitative and qualitative variables, while HCA cannot be performed on qualitative variables. Secondly, we wanted each of the five predetermined dimensions to have the same weight, which was not the case since some dimensions were composed by a higher number of variables than others. In order to overcome these problems, we therefore performed a multiple factorial analysis (MFA) on the 141 defined variables and selected six factors. Using MFA solved our two problems: first, it made it possible to give the same importance to each of the five pre-determined dimensions; secondly, it enabled us to describe each social enterprise through quantitative indicators only (the social enterprise's coordinates on each factor).

The optimal number of clusters (n) resulting from the HCA corresponds to the number of clusters for which the sum of intracluster variances does not decrease significantly when $n+1$ clusters are considered. Based on that criterion, we identified five major clusters. ${ }^{7}$

\subsection{SE Models in Western Europe: Which Profiles and Relevance?}

The key results of our statistical work are displayed in table 20.2 (at the end of section 20.3.3), where the five clusters are described through the various dimensions listed in the first column. The various clusters are analysed here with the following question in mind: to what extent do these clusters confirm or not the existence of our theorised SE models?

\subsubsection{Two Clusters Converging Towards an Entrepreneurial Non-Profit SE Model}

Clusters 1 and 2 gather almost half of the social enterprises in this Western sample and can be considered as corresponding to "entrepreneurial non-profit social enterprises". Cluster 1 gathers organisations providing mainly education, health and social services, whereas social enterprises in cluster 2 are mainly driven by a mission of 
338 Defourny, Nyssens \& Brolis

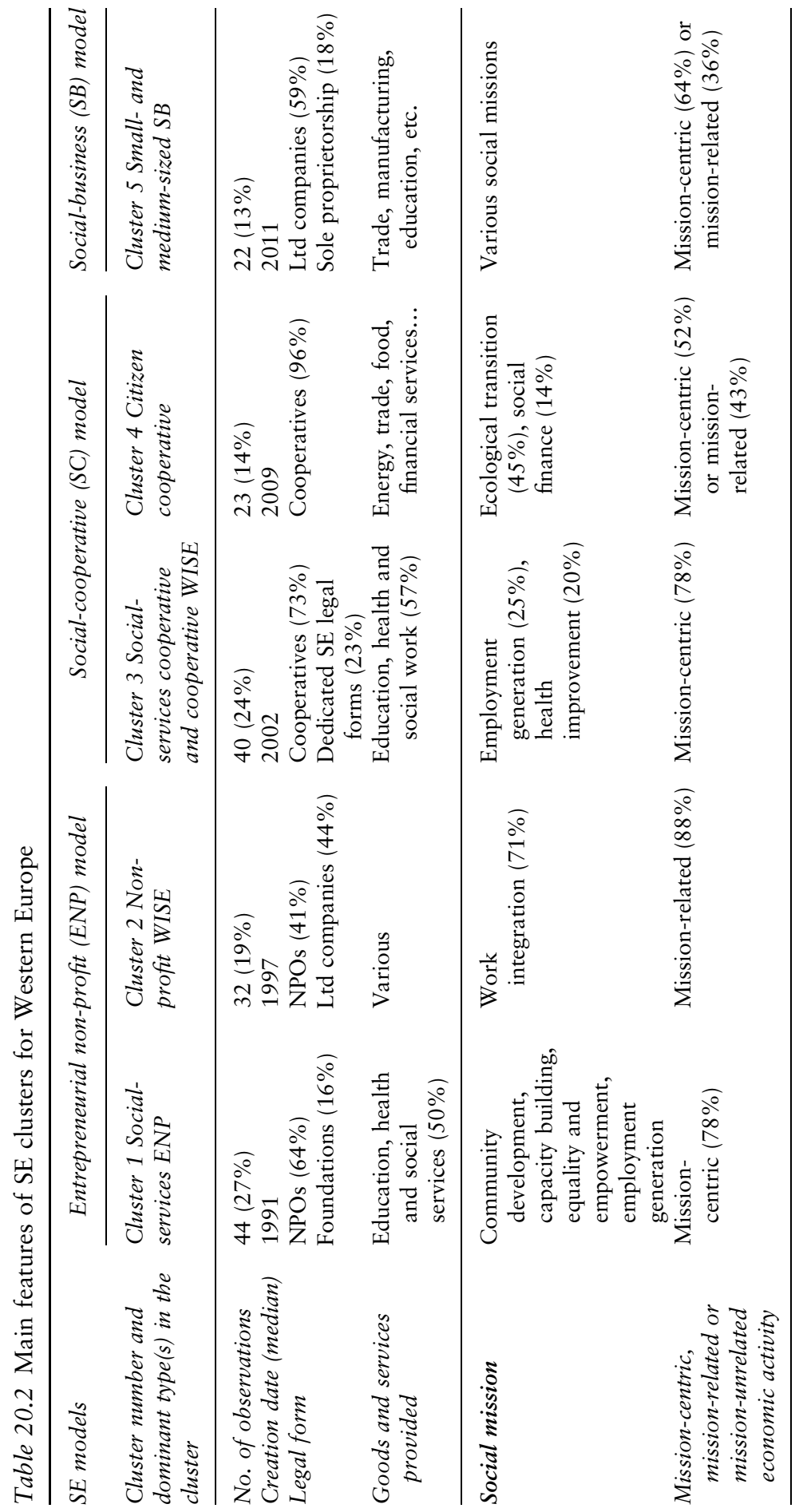


Testing Major SE Models in Western Europe 339

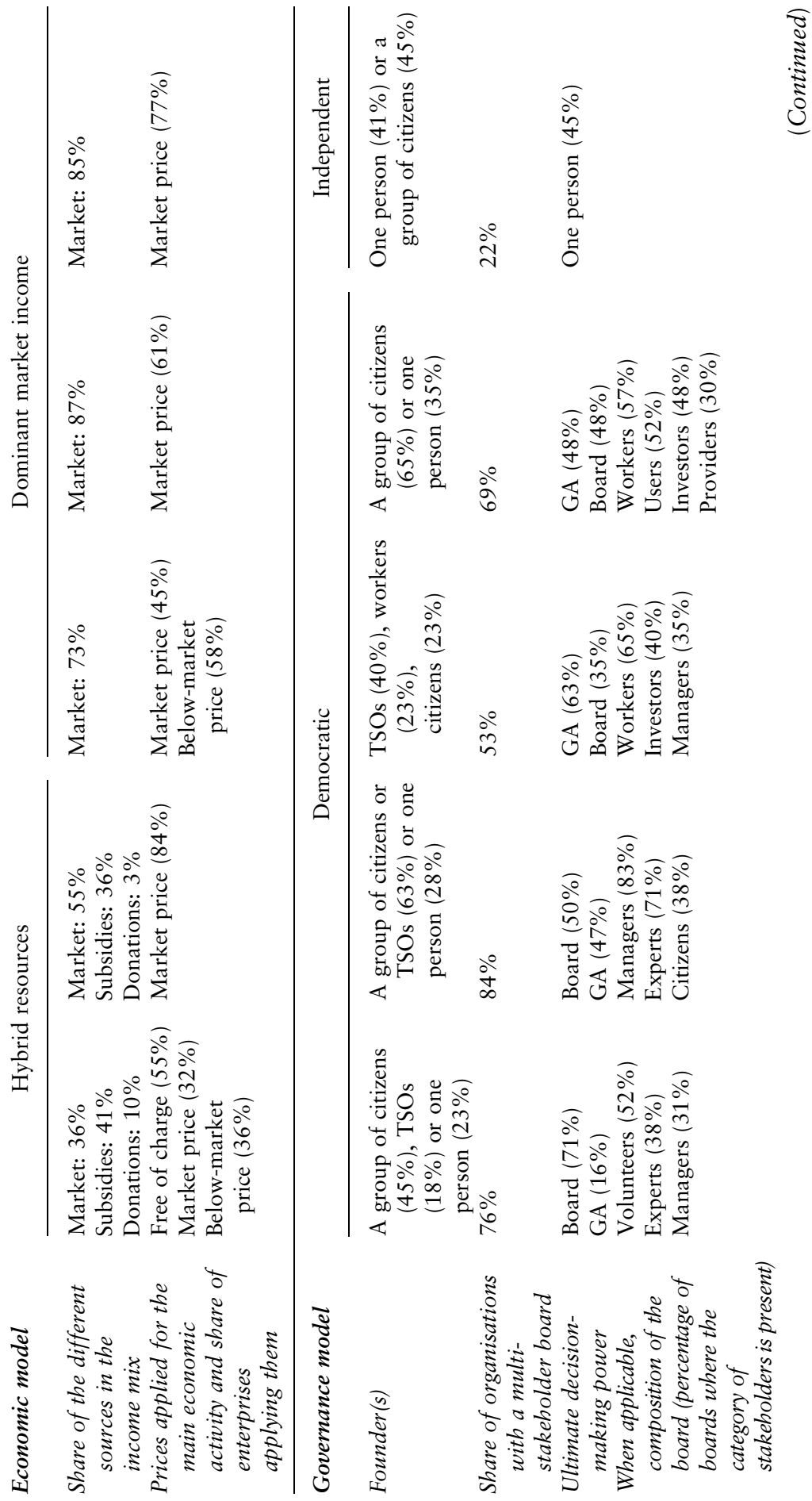




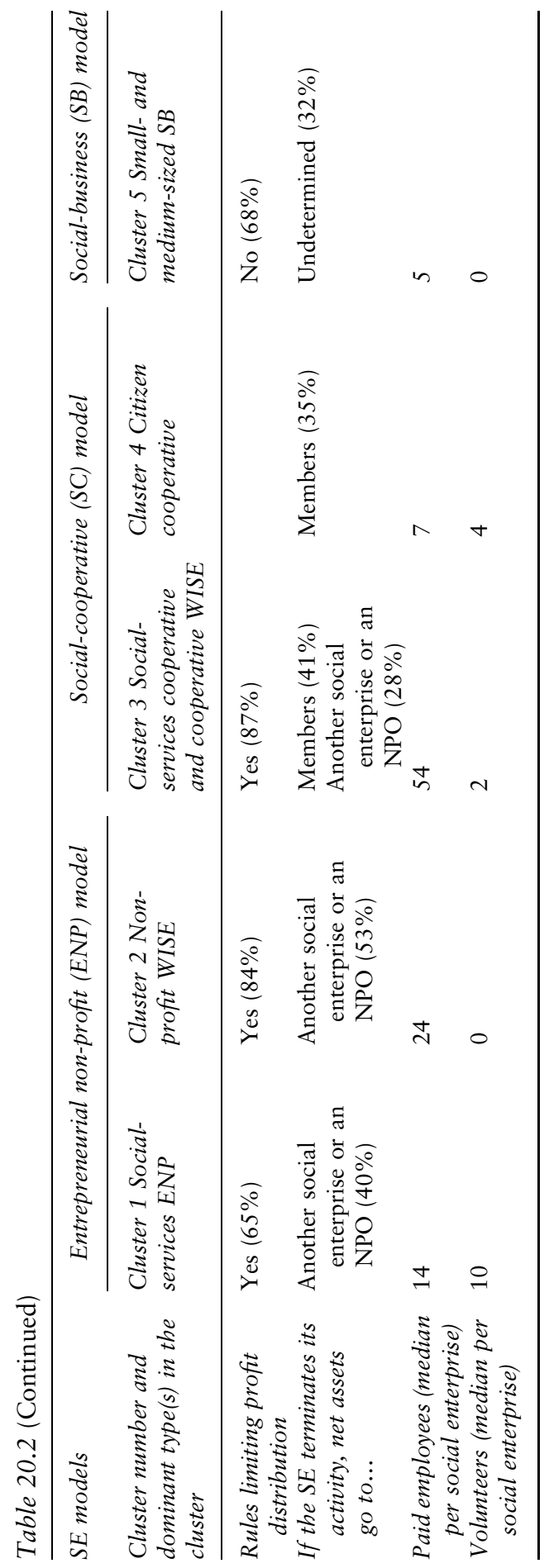


employment generation and may therefore be considered as workintegration social enterprises (WISEs).

In cluster 1 , the dominant legal forms are those of non-profit organisation and foundation. Most enterprises in this cluster have been launched by a group of citizens, sometimes in partnership with another third-sector organisation. In almost one quarter of the cases, a single person is the social enterprise's initiator. These organisations pursue missions such as community development, capacity building, equality and empowerment or employment generation.

Either the board or the GA holds the ultimate decision-making power. In many cases, the board involves volunteers, experts and managers. In $40 \%$ of social enterprises in this cluster, if the activity is terminated, net assets go to another organisation with a similar social mission. Services provided by these social enterprises are mainly "mission-centric", according to Alter's (2007) classification. These organisations have almost as many volunteers as they have employees. Another major distinctive feature of organisations in this cluster is the fact that they are the oldest organisations in the entire sample.

The organisations belonging to this cluster display a wide diversity of resources, with $36 \%$ of income coming from the market and $41 \%$ from public subsidies. Only one-third of these organisations sell some of their services at market price. Indeed, providing at least some services free of charge or at a price not covering most production costs is a widespread practice in this group. In cases where such practice is implemented, the organisation may also receive substantial public subsidies, when its production is considered to contribute significantly to the public good and cannot be financed by private (market and non-market) resources.

Such resource mix could be seen as somehow surprising since a usual approach to social enterprise sees it as "a market solution to a social problem"; in this perspective, the proportion of earned income often constitutes the main indicator to identify social enterprises. For many scholars, however, among which those belonging to the EMES school of thought (Defourny and Nyssens 2010), the entrepreneurial dimension of social enterprise lies, at least partly, in the fact that the initiative bears a significant level of entrepreneurial risk-but not necessarily a market risk. In this broader perspective, the resource mix, which can best support the social mission, is likely to have a hybrid character, as it may combine trading activities with public subsidies and voluntary resources. In a similar way, Maier et al. (2016) identify several dynamics which can characterise "NPOs becoming business-like", beyond the sole market character of financial resources: NPOs can adopt business-like goals (such as commercialisation or/and conversion from an NPO to an FPO legal form); they can also adopt business-like core and support processes (entrepreneurial orientation, professionalisation, business-like philanthropy, etc.) or develop business-like rhetoric. It is thus not surprising 
that many NPOs have been identified as social enterprises by local researchers, even though they have less than $50 \%$ of earned income.

As briefly observed above, cluster 2 gathers mainly work-integration social enterprises (WISEs). The mission of WISEs is to integrate disadvantaged groups back into the labour market and society through a productive activity. In the last two decades, WISEs have been a major focus of policies promoting social enterprise (Nyssens 2006; Cooney et al. 2016). These initiatives sell a wide variety of goods or services, mainly at market price. They rely more heavily on earned income than organisations in cluster 1 , although they are also embedded in a very hybrid economic model. These enterprises' productive activities are mainly "mission-related": indeed, the economic activity is a means to create jobs, whatever the types of products that are commercialised on various markets.

Enterprises in this cluster adopt either the legal form of an NPO or that of a limited company. Most of them have been launched by citizens or third-sector organisations. Like in the previous cluster, a single person is the social enterprise's initiator in about $25 \%$ of cases, thereby reflecting the social entrepreneurial profile of pioneering leaders, who often bring about social innovation or pave the way for new waves of social enterprise. Such social entrepreneurs can be charismatic but they want to adopt democratic governance features. Indeed, either the board or the GA holds the ultimate decision-making power, and the board is composed mainly by managers, experts and citizens. The distribution of profit is limited. If the social enterprise terminates its activity, the net assets are transferred to another social enterprise or to an NPO.

These first two clusters clearly suggest the existence of two major subgroups of social enterprises (one strongly focusing on work integration and another displaying a diversity of other social missions) that share enough features to suggest the existence of a deeply rooted "entrepreneurial non-profit SE model”, covering a spectrum of non-profit social enterprises, as theorised earlier in this volume (see figure 0.1 in the introductory chapter).

\subsubsection{Two Clusters Indicating the Existence of a Social- Cooperative SE Model}

In two clusters among the five (clusters 3 and 4), a large proportion of organisations have adopted the legal form of a cooperative. This is a strong feature, which invites us to look carefully at these two clusters as potentially signalling the existence of a "cooperative-type" SE model. However, we still have to document more strongly the specific "social" nature of enterprises in these clusters, as conventional cooperatives are first and foremost oriented to their members' interests, not the general interest of a larger community, as hypothesised in figure 0.1 . The key 
question is thus the following: how do the organisations belonging to these two clusters differ from conventional cooperatives, to such an extent that they have been regarded as social enterprises by ICSEM researchers, and do their specificity justify their positioning closer to the "social-cooperative" model than to the area of traditional cooperatives?

In cluster 3, about one-fourth of organisations are not legally registered as cooperatives, but this is not necessarily incongruent with our hypothesis of these two clusters signalling the existence of a "cooperativetype" model. Indeed, cooperative principles can also be implemented by social enterprises that are not formally registered as cooperatives. Twenty-three percent of organisations in cluster 3 have adopted dedicated SE legal forms, which vary according to national legislations; some are rather close to-although technically different from-the conventional cooperative status (like the so-called social cooperatives in Italy or the "general-interest cooperative society" in France). In other cases, a label may be combined with various conventional legal forms: until 2018, the "social-purpose company" in Belgium provided a good example of such an SE label that was particularly, although not exclusively, accessible to cooperatives. According to a new law of 2019, only cooperatives now have access to the Belgian SE label. Another case, in the UK, deserves some discussion: since 2008, the British Government has attempted to stimulate development of the "public-service mutual" - a private organisation, characterised by employee rights both to the residual profits and to control. These mutuals thus appear similar to worker cooperatives in that they are oriented to their members' mutual interest; however, they may qualify as social enterprises because they are typically "spin off" from the public sector and provide a public service under contract to a government agency (Le Grand and Roberts 2018). They mostly adopt the legal form of community-interest companies.

The social mission and economic activities are clearly interwoven in the organisations making up cluster 3: almost $80 \%$ of these organisations perform economic activities that are "mission-centric". Organisations in this first cooperative cluster deliver mainly education, health and social services $(57 \%)$-all activities that are meant to serve strong social objectives: they aim mainly at creating jobs for the unemployed or at improving the health of disadvantaged people. These social enterprises rely mainly on market resources ( $73 \%$ of income), although they often sell some of their products below market price, which reflects their general-interest orientation.

In this cluster, most organisations have been launched by third-sector organisations, workers or groups of citizens, and they display democratic governance structures, mainly under the control of their workers and managers (and, in some cases, investors). The distribution of profit is limited or even prohibited in some cases. If the social enterprise terminates its activity, the net assets are transferred to the members or to another social enterprise or NPO. 
With a median workforce of 54 persons, these organisations are the largest social enterprises in the whole sample. On the basis of information not presented in table 20.2, we can add that cluster 3 includes a significant share of Italian social cooperatives, which are emblematic of a legal shift towards a model in which an explicit central place is given to the organisation's general-interest missions. In the late 1980s indeed, in Italy, pioneering cooperative-like initiatives were launched by groups of citizens or workers in the absence of a specific legal form adapted to their characteristics. The conventional cooperative movement, which by then had become aware of new social challenges, decided to support this emerging movement and to lobby for a new type of cooperative, better adapted to these new challenges. Such lobbying led to the development of a supportive ecosystem: creation of a new legal form (namely that of "social cooperative", including "A-type" social cooperatives, targeted at the provision of social services, and "B-type" social cooperatives, which can be considered as work-integration social enterprises), promotion of access to public contracts, etc. A similar movement has since been observed in other European countries, giving birth to social-cooperativetype social enterprises. Indeed, the Italian legal model has since been followed (either fully or partially, with adaptations to national contexts) by the Portuguese (1998), Spanish (1999), Greek (1999) and French (2001) legislators (Fici 2015). ${ }^{8}$

The second cooperative-type cluster (namely cluster 4 ) gathers almost only cooperatives, displaying the typical cooperative governance structure: a general assembly, and an ownership structure based on shares with a cap imposed on profit distribution. They mostly sell their goods and services at market prices.

Initiatives in this cluster are quite recent (about 10 years old) and much smaller than those in the previous cluster. Most of these social enterprises have been launched by citizens. Almost half of them are driven by an ecological transition mission. Moreover, all social enterprises in our sample that are driven by a social mission of "access to financial services" or "food security" are included in this cluster. This cluster also includes, inter alia, short-circuit agricultural cooperatives, gathering producers and consumers of organic food, and renewableenergy cooperatives, where members' interest is combined with a large societal (environmental) aim. Many of these social cooperatives are multi-stakeholder organisations, involving workers, users, investors and providers in their governance bodies.

Overall, these "citizens' cooperatives" involve committed citizens experimenting with social innovations that respond to the interests and values of local communities. As explained by Seyfang and Smith (2007), this type of cooperative strives to fulfil unmet social needs and develops practices based on alternative goals to economic growth per se, such as achieving a higher quality of life or local-community-oriented development. This is 
certainly one of the most recent generation of cooperatives in Western Europe, and it is embedded in the so-called transition movement (Hopkins 2008, 2013).

The analysis of these two clusters leads us to conclude that our theorisation of social cooperative as a major SE model is supported by strong empirical evidence.

\subsubsection{One Cluster Indicating the Existence of a Social- Business Model}

The last and smallest cluster (cluster 5) gathers the most recent and smallest social enterprises in our sample. It may be identified as gathering organisations that combine a strong commercial orientation and a social mission (which, incidentally, may vary a lot from one enterprise to the other). These features, combined with the legal form of limited company or sole proprietorship, indicate the existence of a "social-business" model.

Data in table 20.2 show that organisations belonging to the socialbusiness cluster and those in the two cooperative-type clusters display very similar economic models: they mostly sell their goods and services at market prices and rely on market resources. As far as their activities and missions are concerned, the economic activity of both social cooperatives and social businesses is either "mission-centric" or "mission-related", which means that they deliver goods or services to a wider population than to the group targeted by the social mission.

Beyond these common characteristics, several other features tend to draw the picture of two quite diverging SE profiles. As regards the ultimate decision-making power, in organisations belonging to this last cluster, it most often belongs to the owner. We can qualify this type of ownership and management as "independent", as these social enterprises are in the hands of a single person. This of course contrasts with the "cooperativetype" clusters, whose organisations display democratic governance structures, with a board and a GA involving a wider diversity of stakeholders. Regarding rules and provisions related to profit distribution, it is striking to note that there is no rule limiting profit distribution in $68 \%$ of organisations in the "social-business" cluster (this feature sharply contrasts with what is found in the cooperative-type clusters). These businesses can adopt an accreditation requiring that social goals be predominant in their mission, but generally, such accreditations (e.g., the private accreditation of "benefit corporation" or "B Corp") do not impose any limit on the distribution of profits. This is not to say, however, that all or most of the profits are usually distributed to owners: a quite common practice (shared by $64 \%$ of organisations in the "social-business" cluster) is to reinvest at least part of the profits in the social enterprise. ${ }^{9}$

In order to better capture the actual profile of social enterprises in the "social-business" cluster, more information is still needed, especially 
about their actual size. At first sight, a good deal of the social-business literature emphasises, promotes and celebrates initiatives launched by or in partnership with multinational corporations, thereby suggesting rather large-size initiatives. The annual Global Social Business Summit and its charismatic leader, Muhammad Yunus, are emblematic of this "school of thought", which stresses four key principles: shareholders in social businesses should not expect any financial return on investment (which is easy for big corporations in the framework of a CSR strategy); all profits should be reinvested for the social mission; goods and services should be sold at low prices to reach a high number of poor people; and the absence of public subsidies should guarantee full independence from the state.

It is precisely that kind of profile we had in mind when we started to conceptualise the social-business model, but our statistical results actually suggest another picture. This cluster is made of small- and mediumsized enterprises operating on the market while simultaneously pursuing a social mission. This feature is consistent with the already observed key role of an individual entrepreneur as the initiative's founder, main owner and dominant decision-maker.

As this combination of economic and social goals is implemented here within less regulated frameworks than those defined by the governance rules and structures in "cooperative-type" social enterprises, the balance between these (potentially conflicting) goals and its evolution over time raise the question of the social mission's sustainability. For instance, $32 \%$ of social enterprises in cluster 5 have no predetermined rule about the distribution of net assets in case the activity is terminated. In such context, it seems critical to observe enterprises' actual practices more in depth: To what extent do social and/or environmental dimensions actually prevail over the profit motive? Are they not mere instruments to better serve the financial interests of the owner(s)? More generally, under which conditions can a social-value-generating economic activity be considered as an expression of social entrepreneurship?

In any case, we can, at this stage, state that this cluster provides support to the idea, already represented in our triangle, that the social businessmodel is also deeply rooted in SMEs' willingness to generate blended value.

\subsubsection{No Public or Quasi-Public SE Model?}

Our theoretical typology also included a public or semi-public SE model, whose existence does not appear to be confirmed in Western Europe by the identification of a distinct cluster. However, some enterprises involve a governmental agency among their founding members. Moreover, a previous EMES research project (Nyssens 2006) revealed the importance of the public sector as the sole or as an associate founder of social enterprises in various countries. In Belgium, Germany, Portugal and 
Sweden, for instance, WISEs may be launched by municipalities or other local public bodies getting together to create jobs in various fields, ranging from cleaning services to social housing. A possible interpretation is that, although they do actively support social enterprises, most public authorities prefer to act as partners-rather than as the main entrepreneur-in the creation and management of WISEs. Another explanation for the absence of a distinct cluster confirming the existence of a public-sector SE model may be linked to the personal perception of the SE phenomenon by local researchers: many of them probably considered a priori social enterprises as private entities by nature, and therefore disregarded public-sector initiatives as potential social enterprises.

\section{Conclusion}

The objective of this last chapter was to test the international typology of SE models that we had previously put forward (Defourny and Nyssens 2017). The major finding is that three of our four theorised SE models are strongly supported by empirical evidence: the existence of a social-business model, a social-cooperative model and an entrepreneurial non-profit model is fully confirmed in Western Europe, as these models clearly emerge from the examination of the five clusters resulting from the statistical analysis.

When adding results from the other regions of the world to the picture, ${ }^{10}$ we are able to confirm the relevance of these three SE models, across countries within each region and across regions. More precisely, these three models are found in 39 countries out of 43, and applying the statistical treatment described in section 20.2 to the data from all 721 surveyed social enterprises actually yielded the same major results. ${ }^{11}$ Referring to the hypothesis that we had put forward in this chapter's introduction, we can now assert that our typology of SE models is neither country-specific nor even, more broadly, region-specific.

These results also suggest that social enterprises do stem from most, if not all, parts of the economy and can be related to different organisational backgrounds-namely the non-profit, the cooperative and the business sectors, which exist in all countries. Of course, this does not mean that social enterprises are not influenced by institutional factors at the meso or macro level; on the contrary, SE models should be considered as both embedded in their local contexts and partly shaped by their institutional environment at the meso and macro levels. Moreover, social enterprises themselves actually contribute in turn to shaping their institutional environment, as will be shown in the concluding section of this book.

\section{Notes}

1 In their classic survey of literature on social entrepreneurship, Dacin et al. (2011) listed some 80 references, among which only one referred to social 
enterprise in its title. On the basis of 307 documents selected because they referred to at least one of the notions of "social enterprise", "social entrepreneurship" and "social entrepreneur" such as they understood them, Alegre et al. (2017) developed a citation map and a cluster analysis of definitions; they came out with five quite distinct groups, among which three focused on social entrepreneurship and a single one, quite isolated, focused on defining social enterprise. For their part, Sassmannshausen and Volkmann (2018) provided an overview of the state of art of research on social entrepreneurship and its establishment as an academic field. See also the Journal of Social Entrepreneurship, launched in 2010.

2 See the Social Enterprise Journal, launched in 2005; most research carried out by or in relation to the EMES International Research Network since the late 1990s; and the recent EU report entitled Social Enterprises and their Ecosystems in Europe (2020).

3 Nyssens (2006) is an exception in this regard, as the work she coordinated relied on a common survey covering 162 work-integration social enterprises (WISEs) from eleven EU countries and almost 1,000 "WISE participants", that is, persons engaged in work-integration trajectories.

4 Kerlin's typology is also rooted in a theory trying to explain the existence and the place of the non-profit (third) sector. However, it is not confronted with empirical evidence at the enterprise level.

5 In a few countries where the notion of social enterprise is defined, for instance through a law, the definition does not generally enable an uncontested mapping and statistical analysis, because such a legal approach is often deemed too large or too narrow.

6 Results for Central and Eastern European countries are presented in the ICSEM book which is devoted to this part of Europe (Defourny and Nyssens 2021). Results for Latin America and Asia are presented in the first two ICSEM books, that is, respectively Gaiger et al. (2019) and Bidet and Defourny (2019).

7 One more cluster, gathering three social enterprises, was identified, but it was dropped because these social enterprises could be considered as "outliers".

8 In the same vein, new legal forms or frameworks promoting social cooperatives also appeared in Central and Eastern European countries, such as Hungary (2006), Poland (2006) and the Czech Republic (2012); see Defourny and Nyssens (2021), "Social Enterprise in Central and Eastern Europe".

9 Data upon which this statement is based do not appear in table 20.2; they come from more detailed results of the clustering.

10 See the other three books that resulted from the ICSEM Project, and in particular chapter 16 in Defourny and Nyssens (2021), chapter 16 in Bidet and Defourny (2019) and chapter 11 in Gaiger et al. (2019), for results about respectively Central and Eastern Europe, Asia and Latin America.

11 This global statistical analysis was first carried out and reported by Defourny et al. (2019) in an ICSEM Working Paper and was then published in Nonprofit and Voluntary Sector Quarterly (Defourny et al. 2020).

\section{References}

Alegre, I., Kislenko, S. \& Berbegal-Mirabent, J. (2017) "Organized chaos: Mapping the definitions of social entrepreneurship", Journal of Social Entrepreneurship, Vol. 8, No. 2, pp. 248-264. 
Alter, K. (2007) Social Enterprise Typology, Friendswood: Virtue Ventures LLC. Bidet, E. \& Defourny, J. (eds) (2019) Social Enterprise in Asia. Theory, Models and Practice, London and New York: Routledge.

Borzaga, C. \& Defourny, J. (eds) (2001) The Emergence of Social Enterprise, London and New York: Routledge.

Borzaga, C., Galera, G. \& Nogales, R. (eds) (2008) Social Enterprise: A New Model for Poverty Reduction and Employment Generation, Bratislava: United Nations Development Programme.

Cooney, K., Nyssens, M., O’Shaughnessy, M. \& Defourny, J. (2016) “Public policies and work integration social enterprises: The challenge of institutionalization in a neoliberal era", Nonprofit Policy Forum, Vol. 7, No. 4, pp. 435-460.

Dacin, M. T., Dacin, P. A. \& Tracey, P. (2011) "Social entrepreneurship: A critique and future directions", Organization Science, Vol. 22, No. 5, pp. 1203-1213.

Defourny, J. \& Kim, S.-Y. (2011) "Emerging models of social enterprise in Eastern Asia: A cross-country analysis”, Social Enterprise Journal, Vol. 7, No. 1, pp. 86-111.

Defourny, J. \& Nyssens, M. (2010) “Conceptions of social enterprise and social entrepreneurship in Europe and the United States: Convergences and divergences", Journal of Social Entrepreneurship, Vol. 1, No. 1, pp. 32-53.

Defourny, J. \& Nyssens, M. (2017) "Fundamentals for an international typology of social enterprtise models", Voluntas, Vol. 28, No. 6, pp. 2469-2497.

Defourny, J. \& Nyssens, M. (eds) (2021) Social Enterprise in Central and Eastern Europe. Theory, Models and Practice, London and New York: Routledge.

Defourny, J., Nyssens, M. \& Brolis, O. (2019) “Mapping and testing social enterprise models across the world: Evidence from the 'International Comparative Social Enterprise Models (ICSEM) Project”, ICSEM Working Papers, No. 50, Liege: The International Comparative Social Enterprise Models (ICSEM) Project.

Defourny, J., Nyssens, M. \& Brolis, O. (2020) “Testing social enterprise models across the world: Evidence from the 'International Comparative Social Enterprise Models' (ICSEM) Project”, Nonprofit and Voluntary Sector Quarterly, forthcoming.

European Commission (2020) Social Enterprises and Their Ecosystems in Europe, Comparative Synthesis Report (authors: Borzaga, C., Galera, G., Franchini, B., Chiomento S., Nogales, R. \& Carini, C.), Luxembourg: Publications Office of the European Union.

Fici, A. (2015) "Recognition and legal forms of social enterprise in Europe: A critical analysis from a comparative law perspective", Euricse Working Papers, No. 82/15, Trento: Euricse.

Gaiger, L. I., Nyssens, M. \& Wanderley, F. (eds) (2019) Social Enterprise in Latin America Theory, Models and Practice, London and New York: Routledge.

Gordon, M. (2015) “A typology of social enterprise traditions", ICSEM Working Papers, No. 18, Liege: The International Comparative Social Enterprise Models (ICSEM) Project.

Gui, B. (1991) "The economic rationale for the third sector", Annals of Public and Cooperative Economics, Vol. 62, No. 4, pp. 551-572. 
Hansmann, H. (1996) The Ownership of Enterprise, Cambridge: Harvard University Press.

Hopkins, R. (2008) The Transition Handbook: From Oil Dependency to Local Resilience, Hartford: Chelsea Green Publishing.

Hopkins, R. (2013) The Power of Just Doing Stuff: How Local Action Can Change the World, Cambridge: Green Books.

Kerlin, J. A. (2013) "Defining social enterprise across different contexts: A conceptual framework based on institutional factors", Nonprofit and Voluntary Sector Quarterly, Vol. 12, No. 1, pp. 84-108.

Kerlin, J. A. (ed.) (2017) Shaping Social Enterprise: Understanding Institutional Context and Influence, London: Emerald Publishing Group.

Le Grand, J. \& Roberts, J. (2018) “The public service mutual: Theories of motivational advantage", Public Administration Review, Vol. 78, No. 1, pp. 82-91.

Maier, F., Meyer, M. \& Steinbereithner, M. (2016) “Nonprofit organizations becoming business-like: A systematic review. Nonprofit and Voluntary Sector Quarterly, Vol. 45, No. 1, pp. 64-86.

McMurtry, J. J. \& Brouard, F. (2015) "Social enterprises in Canada: An introduction", Canadian Journal of Nonprofit and Social Economy Research, Vol. 6, No. 1, pp. 6-17.

Nyssens, M. (ed.) (2006) Social Enterprise: At the Crossroad of Market, Public Policies and Civil Society, London: Routledge.

Salamon, L., Sokolowski, W. \& Anheier, H. (2000) "Social origins of civil society: An overview", Working Paper of the Johns Hopkins Comparative Nonprofit Sector Project, No. 38, Baltimore: The Johns Hopkins Center for Civil Society Studies.

Santos, F. M. (2012) "A positive theory of social entrepreneurship", Journal of Business Ethics, Vol. 111, No. 3, pp. 335-351.

Sassmannshausen, S. \& Volkmann, C. (2018) "The scientometrics of social entrepreneurship and its establishment as an academic field", Journal of Small Business Management, Vol. 56, No. 2, pp. 251-273.

Seyfang, G. \& Smith, A. (2007) "Grassroots innovations for sustainable development: Towards a new research and policy agenda", Environmental Politics, Vol. 16, pp. 584-603.

Spear, R., Cornforth, C. \& Aiken, M. (2009) "The governance challenges of social enterprises: Evidence from a UK empirical study", Annals of Public and Cooperative Economics, Vol. 80, No. 2, pp. 247-273.

Teasdale, S. (2012) "What's in a name? Making sense of social enterprise discourses”, Public Policy and Administration, Vol. 27, No. 2, pp. 99-119.

Young, D., Searing, E. \& Brewer, C. (eds) (2016) The Social Enterprise Zoo, Cheltenham: Edward Elgar Publishing. 